\title{
Recycling of Tar Decanter Sludge through the addition of coke oven batteries in charge coal feed
}

\author{
Y. Singh, S. T. Selvan, S. K. Ghosh \& A. K. P. Singh \\ $R \& D$ Centre for Iron \& Steel, Steel Authority of India Limited, \\ Ranchi-834 002, Jharkhand, India
}

\begin{abstract}
Toxic Tar Decanter Sludge previously dumped at the Bokaro Steel Plant, Steel Authority of India Limited (SAIL), is now recycled to the coke ovens via the coal charge. Not only has an environmental pollutant been removed but savings of US \$ 0.15 million a year have resulted due to carbon recovery. Based on encouraging results at Bokaro, other SAIL plants have undertaken the implementation of the system. This paper depicts details of the generation of tar decanter sludge, the modified recycling system, the design features, the novelty in the system, the modifications, and the economic benefits.
\end{abstract}

Keywords: tar decanter sludge disposal, recycling, waste utilisation, environmental protection, economic utilisation of waste.

\section{Introduction}

Tar Decanter Sludge (TDS) is generated as a by-product of coke oven gas. Disposal of TDS is difficult because it is a sticky material and it easily melts during the Indian summer. When melted, it spreads and further pollutes the disposal area. The generation of TDS at Bokaro Steel Plant is approximately $200 \mathrm{t} / \mathrm{month}$. The TDS is collected from the decanter in a specially designed pot. The former practice was to lift the pot using a dumper placer, carry it outside the plant premises and empty it by inverting the pot.

The R\&D Centre for Iron \& Steel (RDCIS), Steel Authority of India Ltd. (SAIL) has designed, installed and commissioned a system, which has led to utilization of the TDS by feeding it to the coal charge on the conveyor belt from where it is distributed to the various coke oven batteries. The use of TDS in the 
coal charge not only solves the pollution problem but also has added carbon value to the coal charge, which was otherwise being wasted. Moreover, addition of TDS to the coal feed has formed a close network with the coke oven production flow, which has facilitated recirculation of a waste product and so removed an environmental pollution problem and thereby helped fulfil statutory environmental regulations.

The system was commissioned in June 2001 and has operated successfully since then and has provided substantial techno-economic benefits. It is capable of adding TDS at the rate of up to five tonnes per hour, more than sufficient to deal with the eight tonne daily output of TDS.

\section{Generation of Tar Decanter Sludge}

During coke making, coke oven gas containing many organic compounds is generated as a by-product. Tar is one such organic compound, which is collected from decanter tank. Bokaro Steel Plant has five tar decanter tanks. Sludge accumulates at the bottom of the tanks by gravity separation. This is removed using a scraper conveyor and collected in a sludge pot. About 200t/month of sludge is generated by the plant.

The previous practice of charging the sludge not only leads to a pollution problem but also is wasteful as the sludge contains a large amount of carbon particles of high fuel value. Also the TDS contains various toxic organic compounds, which are classified as hazardous waste within the Hazardous Waste Management and Handling Rules. Utilisation of this sludge obviates the environmental pollution problem and simultaneously adds to the carbon value of coal charge.

Tar decanter sludge is being used to improve coke quality at many places. Spraying of tar decanter sludge on to the coal charge is practiced in Australia, Russia, Brazil, etc. Within India, it is practiced at Rashtriya Ispat Nigam Ltd., Vishakhapattanam. In the system installed at Bokaro Steel Plant, the tar decanter sludge is transported to the TDS disposal plant in the TDS pot by means of a dumper placer. The TDS pot is then lifted by means of an auxiliary hoist so as to deposit the TDS into a suitably designed bunker (Figure 1). From the bunker bottom outlet the TDS is carried by a horizontal screw conveyor to its discharge coal to the main conveyor belt, which distributes the charge to the various batteries. Table 1 summarises the properties of the sludge and operation.

Five decanters each of $700 \mathrm{~m}^{3}$ capacity separate the constituents of the flushing liquor and crude tar. The decanters are provided with hoppers each of two tonnes capacity to receive TDS. TDS pots of four tonnes capacity are moved beneath the hopper and the sludge emptied into them via a scraper conveyor.

\section{Modified system}

The system designed has ensured uniform discharging of the TDS over the coal charge. A bunker of $6.5 \mathrm{~m}^{3}$ capacity is installed near the auxiliary belt conveyor feeding the main conveyor to the batteries. A steam pipe network inside the 


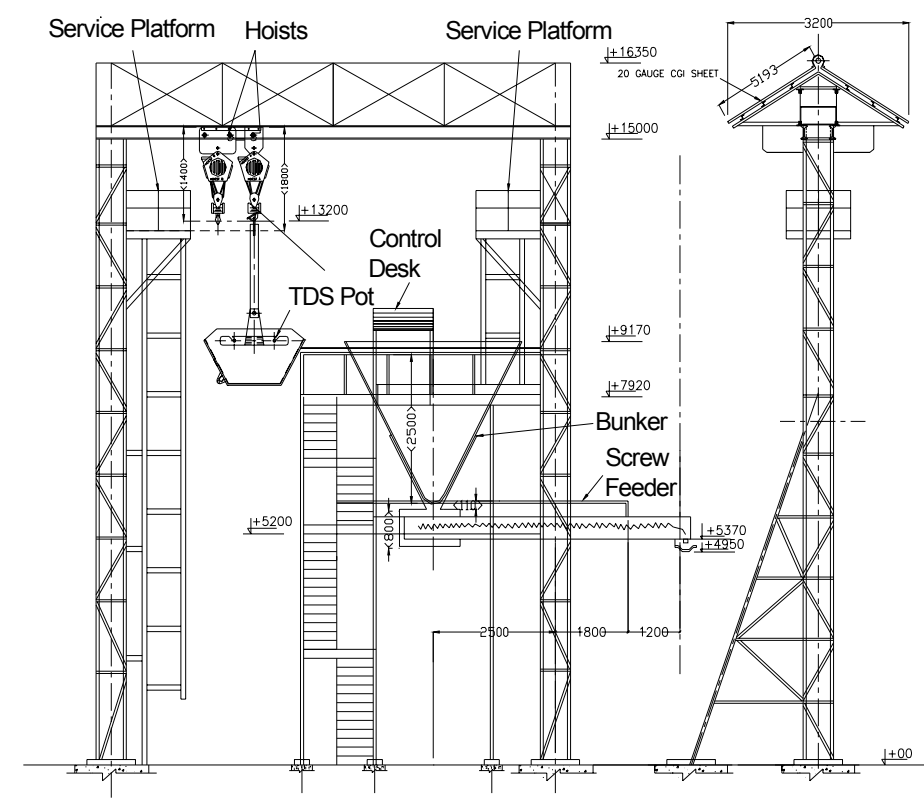

Figure 1: Recycling system to feed TDS on to coal for the coke oven.

Table 1: Design basis for the tar decanter sludge disposal system.

\begin{tabular}{|l|c|}
\hline Description & Specifications \\
\hline Total no. of tar decanter tanks at BSL & 5 of 700m3 capacity each. \\
\hline Total quantity of TDS production & 8 TPD / 200 t per month. \\
\hline Specific gravity of TDS & 1.28 \\
\hline Viscosity of TDS & $1100 \mathrm{CPS}$ \\
\hline Viscosity of tar & $550 \mathrm{CPS}$ \\
\hline Steam quality & Saturated at $4-5 \mathrm{~kg} / \mathrm{cm}^{2}$ \\
\hline
\end{tabular}

TPD: tonnes per day.

CPS: centipoise.

bunker supplies heat to ensure the TDS is sufficiently fluid and also the TDS discharged from the pot must pass through a $50 \mathrm{~mm}$ mesh of steam pipes across the mouth of the bunker, which melts any large piece of solidified TDS passing from the pot to the bunker. The pot is required to be tilted to $140^{\circ}$ for complete discharge. The necessary support/tilting arrangements have been provided for this purpose. After discharge of the sludge, the TDS pot is brought to the ground by means of the main hoist. The monorail hoist is released after placing the pot either on the ground or on the dumper.

A screw conveyor transports the sludge from the bunker outlet to the auxiliary conveyor carrying coal to the main conveyor for distribution to the various coke 
oven batteries. The screw conveyor is provided with steam heating to maintain the fluidity of the TDS.

The sludge is discharged on to the coal charge on the conveyor belt via a ploughing arrangement placed before and after the sludge feeding point so that the discharged sludge is contained within the coal feed and does not come into contact with the belt during transportation.

An electro-mechanical system senses the presence of coal on the conveyor belt and is interlocked with the screw feeder to ensure that sludge is not fed on to an idle or empty belt.

The steam required to heat the bunker and screw feeder is tapped from a $50 \mathrm{~mm}$ steam pipeline near the working zone. Strainers are provided in the supply line to remove foreign elements. Steam traps have also been provided at the exist point and the exit lines are connected to an underground waste water line for disposal. The system is able to feed the TDS to the conveyor belt at the rate of $5 \mathrm{t} / \mathrm{h}$ with a variation of $\pm 0.5 \mathrm{t} / \mathrm{h}$.

\section{Design features}

TDS Bunker: The bunker volume is $6.5 \mathrm{~m}^{3}$ and it is $2.5 \mathrm{~m}$ high. It is steam heated through pipes to keep the sludge flowing. The angle of repose of the bunker ensures the TDS flows readily. A mesh of steam-heated pipes across its top ensures that any large blocks of sludge (greater than $100 \mathrm{~mm}$ ) cannot enter the hopper discharge and choke the flow. The mouth of the bunker is sufficiently large to avoid any spillage when emptying the TDS pot.

Screw Feeder: The screw feeder of $6.0 \mathrm{t} / \mathrm{h}$ capacity conveys the TDS from the bunker to the auxiliary coal conveyor belt.

Mono-rail Hoist: The mono-rail hoist lifts the TDS pot to a height of $9.5 \mathrm{~m}$ to the top of the bunker and tilts to about $140^{\circ}$ for easy discharge of the TDS into the bunker. This dual function is performed through specially designed hoists consisting of a main hoist of $10 \mathrm{t}$ capacity and an auxiliary hoist of $5 \mathrm{t}$ capacity. The main hoist is used to lift the pot and the auxiliary hoist tilts it. Both hoists can work together or independently. Operation of the hoist is by a pendant switch.

\section{Novelty in the system}

Recycling of tar decanter sludge was practiced in USSR, Brazil, Australia, etc. In India, it is being practiced at Rashtriya Ispat Nigam Limited (RINL), Vishakhapatnam. In all the places, the system consists of underground bunker for receiving the sludge. The sludge is unloaded to the underground bunker with the help of the dumper. This is then discharged to scrapper conveyor, which in turn feeds the sludge to the coal charge on conveyor belt from where it is distributed to different batteries of the coke oven plant. This system is laden with various maintenance as well as operational problems because of underground installations. As a result, the recycling of the sludge is interrupted very frequently. In the system designed by RDCIS, SAIL, the sludge is 
transported to the disposal plant from where it is lifted with the help of specially designed mono rail double hoist to the required height and discharged to the top of the bunker which is $+10 \mathrm{~m}$ above ground level. Maintenance is easier and there are no operational problems. Because of this continuous operation and recycling is being done in our system designed and installed at Bokaro.

In the earlier system, scrapper conveyor is used whereas in our system screw conveyor is used. The screw conveyor is more accurate in controlling the feed rate required for proper as well as uniform mixing of the sludge with the coal charge.

In the earlier system, there is no indication of availability of coal charge on conveyor belt and because of this there are chances of sludge being fed on empty conveyor belt, which in turn spoils the belt. This also causes interruption of recycling of the sludge as well as total production process and monetary loss. In our system electro-mechanical sensing system has been designed and installed. This facilitates sensing of load on the conveyor belt. The sensing of load on conveyor indicates availability of coal charge and no load indicates that the belt is empty. The sensing of loads as well as the running of the conveyor is electronically linked with the operation of sludge feeding system. Because of this the sludge is never fed to the empty conveyor and at the same time it is never fed on idle condition of the conveyor i.e. during stoppage of the coal-carrying conveyor under operational requirements. This leads to avoidance of the operational and maintenance problems prevalent in the earlier system.

\section{Modification to original}

Space for the foundations was the main constraint in designing the system as well as during installation of the structures. Only $1.2 \mathrm{~m}$ of clearance was available between the underground waste water line and a cable gallery. Other locations were interfering with existing installations.

The installation site is surrounded on three sides by the main Y-29 conveyor belt taking coal to the various batteries, the Y-20 auxiliary belt carrying the coal on to which the TDS is discharged and by coke oven gas pipelines. The structure of the modified system was about $16 \mathrm{~m}$ total height and was erected within the space available after provision of suitable clearance.

The existing TDS pots were modified by the addition to lugs for lifting and tilting.

A ploughing arrangement was provided on the auxiliary conveyor belt structures.

The water supply line was re-routed to provide clearance for the screw conveyor over the auxiliary belt. The asbestos enclosure over the auxiliary belt was modified to suit the installation of the main structural column.

\section{Economic benefits}

The system was installed at Bokaro Steel Plant at a cost of around $\$ 80000$ and has operated continuously since commissioning in September 2001. The 
utilisation of sludge at Bokaro Steel Plant from September 2001 to December 2007 is shown in Table 2. Based on the above utilisation the average monetary benefits accrued is of the order of US\$0.15 million a year. Over and above the monetary benefits, the system has ensured total recycling of the sludge and thereby removed an important environmental pollution problem.

Table 2: $\quad$ Utilisation of TDS at BSL, Bokaro, since September 2001.

\begin{tabular}{|l|c|}
\hline Period & Addition of TDS in coal charge (tonnes) \\
\hline $2001-02$ & 1690.00 \\
\hline $2002-03$ & 1450.00 \\
\hline $2003-04$ & 1235.00 \\
\hline $2005-06$ & 1315.00 \\
\hline $2006-07$ & 0750.00 \\
\hline $2007-08$ & 0485.00 \\
\hline Total & 6925.00 \\
\hline
\end{tabular}

\section{References}

[1] Yu. S. Nagoruyi, V. M. Gulyaev, and L. I. Glushchenko, Use of Tar Containing Waste Product from By-product Coke Production in Coking Charge, Koks I Khimiya (Coke and Chemistry), no. 1, pp. 14-16, 1986.

[2] Bethelhem Steel, Environmental Control in Steel Industry, International Iron and Steel Institute, 120, B-1140, Brussels Belgium, pp. 166-171, 1992.

[3] CF Systems, Iron-making Conference Proceedings, vol-49, Detroit, Michigan, USA, pp. 183-188, 1990.

[4] ABS Enterprises, Bhattacharya A., Cericola D.L., Hohman M.E., Jageman III T.M., Martin D., Iron and Steel Engineer 75, (5), pp. 30-33, May, 1998.

[5] Drawings and Documents of Coke Ovens and By-product Plant, BSL, Bokaro. 